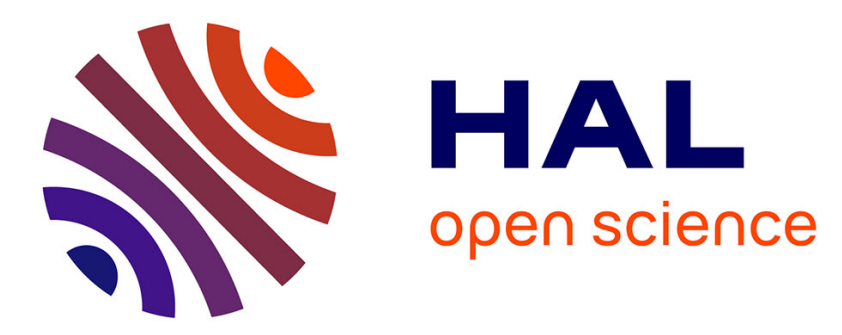

\title{
Chronic ataxic neuropathies associated with anti-GD1b IgM antibodies: Response to IVIg therapy
}

\author{
Shahram Attarian, José Boucraut, Anne Marie Hubert, David Uzenot, \\ Emilien Delmont, Annie Verschueren, Jerome Franques, Jean-Philippe Azulay, \\ Jean Pouget
}

\section{To cite this version:}

Shahram Attarian, José Boucraut, Anne Marie Hubert, David Uzenot, Emilien Delmont, et al.. Chronic ataxic neuropathies associated with anti-GD1b IgM antibodies: Response to IVIg therapy. Journal of Neurology, Neurosurgery and Psychiatry, 2009, 81 (1), pp.61. 10.1136/jnnp.2009.185736 . hal-00552791

\section{HAL Id: hal-00552791 \\ https://hal.science/hal-00552791}

Submitted on 6 Jan 2011

HAL is a multi-disciplinary open access archive for the deposit and dissemination of scientific research documents, whether they are published or not. The documents may come from teaching and research institutions in France or abroad, or from public or private research centers.
L'archive ouverte pluridisciplinaire HAL, est destinée au dépôt et à la diffusion de documents scientifiques de niveau recherche, publiés ou non, émanant des établissements d'enseignement et de recherche français ou étrangers, des laboratoires publics ou privés. 
Title: Chronic ataxic neuropathies associated with anti-GD1b IgM antibodies:

Response to IVIg therapy

Authors: S Attarian ${ }^{1, \S}$ MD, PhD; J Boucraut ${ }^{3 \S}, \mathrm{MD}, \mathrm{PhD} ; \mathrm{AM}$ Hubert $^{3} \mathrm{PhD}$; D Uzenot1, MD; E Delmont $^{4}$, MD; A Verschueren ${ }^{1}, \mathrm{MD} ; \mathrm{J}_{\text {Franques }}{ }^{1}, \mathrm{MD} ; \mathrm{JP}$ Azulay $^{2 *} \mathrm{PhD}, \mathrm{MD}, \mathrm{J} \mathrm{Pouget}^{1 *}$, MD.

(1) Department of Neurology and Neuromuscular Disorders, CHU La Timone

(2) Department of Neurology and Movement Disorders, CHU La Timone

(3) Department of Immunology, CHU Conception, 13385 Marseille and UMR CNRS 6231

(4) Physical Therapy and Neuromuscular Department, CHU L'Archet 1, 06202 Nice, France

*,§ These authors contributed equally to the work presented in this article.

Correspondence: Shahram Attarian, Department of Neurology and Neuromuscular Disorders, CHU La Timone. 264 rue St Pierre, 13385, Marseille, France

E-Mail: sattarian@ap-hm.fr

Tel: (334)91386579

Fax: (334)913864946

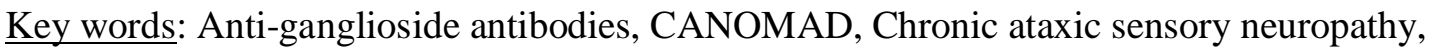
Demyelinating neuropathy, intravenous immunoglobulin.

Word count: Title: 93 characters with spaces; Abstract: 250, text: 2396, References: 31; Tables 2. 
List of abbreviations used in the text

AAN, American academy of neurology

CANOMAD, chronic ataxic neuropathy, ophthalmoplegia, IgM paraprotein, cold agglutinins and disialosyl antibodies

CIDP: chronic inflammatory demyelinating polyradiculopathy

CSF, cerebrospinal fluid

EMG, electromyography

INCAT, inflammatory neuropathy causes and treatment

IVIg, intravenous immunoglobulin

MMN, multifocal motor neuropathy

NCS, nerve conduction study 


\section{ABSTRACT}

Objective: to determine the responses to treatment of patients with chronic sensory ataxic neuropathy associated with anti- GD1b IgM antibodies.

Methods: patients with chronic sensory ataxic neuropathy associated with anti- GD1b IgM antibodies followed in our department for at least 12 months between 2001 and 2008 were identified and studied retrospectively. Patients were tested at regular intervals using the INCAT disability score. Patients whose disability scores improved by at least one point were taken to have responded to the treatment. Intravenous immunoglobulin (IVIg; $2 \mathrm{~g} / \mathrm{kg}$ ) was administered for 3 to 5 days once every 6 weeks or corticosteroids at an initial daily dose of 1 $\mathrm{mg} / \mathrm{kg}$.

Results: 13 patients treated during the 8 -year period of interest were included in this study. 7 of 13 patients displayed IgM anti-GQ1b, GT1b and GD3 antibodies suggesting reactivity against disialosyl epitope. IgM gammopathy was detected in 4 of 6 of serum with antidisialosyl antibodies and 2 of the 7 other sera. 9 of the 13 patients improved in response to IVIg. Oral corticosteroid treatment was attempted on 4 patients prior to IVIg treatment, and partial recovery occurred in one, who became steroid-dependent and showed little benefit in the long term.

Conclusions: Screening for anti-GD1b IgM antibodies should be carried out on all patients with chronic ataxic sensory neuropathies. In $69 \%$ of the cases studied, the patients' condition improved in response to IVIg. This study shows the short term efficiency of this treatment. Sustained responses were obtained in the long term by continuing the infusions. 


\section{INTRODUCTION}

Acquired sensory neuropathies are associated with Sjögren's syndrome, diabetes mellitus, amyloidosis, infections, exposure to neurotoxic medications, and anti-antiglycolipids autoantiodies. Neuropathies associated with immunoglobulin $\mathrm{M}(\operatorname{Ig} M)$ antibodies against disialosyl residues have been defined ${ }^{1-8}$ as either sensory ataxic neuropathy associated with anti GD1b IgM antibody, ${ }^{9}$ chronic sensory ataxic neuropathy associated with anti-disialosyl IgM antibodies, or chronic ataxic neuropathy involving ophthalmoplegia, IgM paraprotein, cold agglutinins and disialosyl antibodies (CANOMAD). ${ }^{10}$ The most prominent feature of these neuropathies is sensory ataxia with relatively well preserved muscle strength and smallfiber sensation. An immunohistochemical study showed localization of GD1b in the neurons of human dorsal root ganglia. ${ }^{11,12}$ Moreover, experimental sensory neuropathy is induced by sensitization with monospecific GD1b. ${ }^{13}$ GD1b, therefore, is recognized as putative target molecule for serum antibodies. Only few cases, however, has been reported of chronic sensory dominant polyneuropathy associated with IgM antibody specifically to GD1b, and report therapeutic responses of patients with GD1b associated sensory neuropathies. Plasmapheresis improved about some of the patients treated, ${ }^{1,14}$ whereas only a few of the

patients treated with corticosteroids improved. 5, 9, 11, 15-21 Intravenous immunoglobulin (IVIg) has been used in a few cases, ${ }^{9}, 16,17,19,21$ and half of these patients improved. Anti-CD20 antibody has been attempted successfully on one patient. ${ }^{21}$ The aim of this study was to document the responses to immunotherapy of patients with chronic sensory ataxic neuropathy associated with anti- GD1b IgM antibodies. 


\section{METHODS}

\section{Study design}

Patients with chronic sensory ataxic neuropathy associated with abnormally high anti- GD1b IgM antibody levels (normal $\leq 20$ ) who were followed in our department for at least 12 months between 2001 and 2008 were identified retrospectively. We excluded other known causes of sensory ataxic neuropathy such as Sjögren's syndrome, diabetes mellitus, amyloidosis, infections, exposure to neurotoxic medications, and anti-myelin associated glycoprotein autoantiodies. Patients were tested at regular intervals using the INCAT disability score. $^{22}$ The treatment consisted of a course of IVIg ( $2 \mathrm{~g} / \mathrm{kg}$ infusions administered during 3 to 5 days once every 6 weeks on average or corticosteroids at an initial daily dose of $1 \mathrm{mg} / \mathrm{kg}$ for at least 6 weeks. The frequency of IVIg administration during the follow-up period was tailored to each patient on the basis of clinical examinations and their ability to carry out their everyday activities. Improvement was defined here as a persistent decrease of at least one point in the INCAT disability score. ${ }^{22}$ An INCAT disability score equal to 1 had to be exclusively from leg disability to be eligible for this study.

\section{Biology}

The presence of anti-GD1b, -GQ1b, -GM1, -GD1a, GD3, GT1b and -GM2 antibodies was tested routinely using ELISA methods as described previously. ${ }^{23,}{ }^{24}$ Positive thresholds were defined for each test as the mean value +3 standard deviations of the results obtained with 50 sera from normal blood donors diluted at $1 / 20$. Serial dilutions were prepared from all sera giving values above the threshold value. ELISA results were expressed as the inverse of the last dilution giving a value above the threshold. Disialosyl profile were also tested with a dotblot method (GA, Dahlewitz, Germany). Monoclonal gammopathy detection was performed 
using the immunofixation method (SEBIA) with an adapted procedure in order to enhance the threshold of detection of IgM monoclonal gammopathy.

\section{Nerve Conduction Study}

All the patients included in this study underwent at least one nerve conduction study (NCS) and needle EMG in our department using a Viking Select EMG machine (Nicolet, Madison, WI) or a Keypoint EMG Machine (Alpine bioMed, USA), with standard procedures. Motor NCS included median, ulnar, peroneal, and tibial motor responses and median, ulnar, superficial radial, and sural sensory responses. Measurements included distal latency, negative-peak duration, baseline-to-peak amplitude, conduction velocity, and minimal F-wave latencies. Two or more different NCS investigations were performed on 10 patients. Patients were taken to have demyelinating neuropathy if they fulfilled the Ad Hoc Subcommittee of the American Academy of Neurology (AAN) AIDS Task Force 1991 criteria. $^{25}$

\section{Data Analysis}

Statistical analyses were performed with the JMP software program (SAS Institute Inc, Cary, NC). The Kruskal-Wallis test was used to test the significance of the differences in the variables between groups. The significance level was set at $\mathrm{P}<0.05$. 


\section{RESULTS:}

\section{Clinical Features}

Thirteen patients were included in this study for the period between 2001 and 2008. The main clinical characteristics are shown in table 1 . There were 7 men and 6 women, aged 54.4 years on average (range: 36 to 75 years). The mean follow-up time was 45 months (range: 17 to 96 months). First symptoms were paresthesis and hypoesthesia in 12 of the 13 patients (in the lower limbs in 7 cases, in the upper limbs in 3 cases, and in both upper and lower limbs in 1 case). Ataxia, which was the first symptom to occur in one patient, developed later in all the other patients. Pinprick and temperature sensations were impaired with a glove-stocking distribution in 8 of the 13 patients, these symptoms occurred only distally in the lower limbs in 4 of the 13 patients, and the results were normal in one patient. Perception of vibration was impaired in the lower limbs of all the patients, and was associated with impairments in the upper limbs in 6 patients. Areflexia was diffuse in 7 patients, restricted to the lower limbs in 2 and restricted to the ankles in 4 patients. In 10 of the 13 patients, no motor weakness was associated with the sensory impairments. The onset of the pathology was acute in 2 patients, progressive - recurrent in 4 patients and progressive in 7 patients.

\section{Laboratory Findings}

The sera testing showed a profile suggesting the presence of antibodies against disialosyl epitope shared by GD1b, GD3, GT1b and GQ1b for of 6 of the 13 patients. Disialosyl profile were also observed with a dot-blot method. The other sera revealed the presence of anti-GD1b $\operatorname{IgM}$ without or with $(n=2)$ reaction with GQ1b. All tests for $\operatorname{IgG}$ antibodies were negative excepted for sera of patient 8 and 10 which are positive for IgG anti-GD1b. 
IgM monoclonal gammopathy was observed in 6 patients, associated with a kappa light chain in 5 patients, and a lambda light chain in one patient. Only one patient had an increase of total IgM level (patient 11: $11.4 \mathrm{~g} / \mathrm{l}$. Cold agglutinins were tested in 11 patients and found to be present in 4 of them. Cerebrospinal fluid (CSF) analysis performed on 12 patients showed the presence of slightly higher than normal CSF protein levels in 7 patients (normal $\leq 0.55 \mathrm{~g} / \mathrm{l}$; Table 2), 3 of whom had demyelinating neuropathy.

The anti-disialosyl group comprised six patients (nos. 1-6; Tables 1 and 2). Cranial nerve involvement was found to be present in 4 patients. This symptom occurred several years after the onset of the sensory symptoms ( 24 to 120 months later).

\section{Nerve Conduction Studies}

The last NCS was performed 60 months on average after the onset of the symptoms. At the last NCS, sensory neuropathy associated with decreased or abolished sensory potentials was detected in all 13 patients. Sensory action potentials were impaired in the lower limbs in 3 patients and in both upper and lower limbs in 10 patients. At the first NCS (based on the data available on 10 patients), sensory NCS was normal in 1 out of 10 patients, showed the presence of abnormalities in the lower limbs in 3 out of 10 patients, and abnormalities in all four limbs in 6 out of 10 patients. Motor NCS was normal or near normal in 9 of the 13 patients. Motor NCS findings showed the presence of demyelinating neuropathy in 3 of the 13 patients, based on the AAN electrophysiological criteria (Table 2). Two of these 3 patients had anti-GM1 IgM autoantibodies. Only one patient had NCS findings suggesting the presence of an axonal sensori-motor neuropathy. In 2 patients, the last NCS study showed the presence of a demyelinating neuropathy, whereas the previous examination conducted several years earlier showed mild abnormalities. 


\section{Response to Immunotherapy}

IVIg infusions were attempted on all 13 patients. The therapeutic responses are shown in table 1. Twenty-four $2 \mathrm{~g} / \mathrm{kg}$ IVIg were performed on average (range: 3 to 100 infusions) per patient at a rate of one 3- to 5-day infusion every 4 to 8 weeks. We did not use lower doses as part of maintenance infusion. The INCAT disability score was improved by at least one point in response to IVIg infusions in 9 of the 13 patients (69\%). This improvement was sustained in 6 of these 9 patients, whose condition continued to improve while undergoing IVIg infusions at a mean rate of one $2 \mathrm{~g} / \mathrm{kg}$ IVIg infusion every 6.5 weeks (range: 4 - 8 weeks). Three of the 6 patients whose improvement persisted had a demyelinating neuropathy according to AAN criteria. The improvement which occurred in 2 patients in response to IVIg infusions persisted without any further IVIg infusions (after 18 months in the case of patient 9 and 60 months in that of patient 1). All 3 patients with demyelinating neuropathy and 6 of the 10 patients with no features of demyelinating neuropathy improved in response to IVIg treatment. One patient (no. 3) was lost to follow-up.

Oral corticosteroid treatment was attempted on 4 patients (patients 4, 5, 7, and 13) prior to IVIg treatment (from 6 weeks to 6 months prior to the treatment), and partial recovery occurred in one, who became steroid-dependent and showed little benefit in the long term (patients 5). Azathioprine was used in 3 patients with no success. 


\section{DISCUSSION}

Little is known so far about the response to immunotherapy of patients with chronic ataxic neuropathies associated with anti-GD1b IgM. IVIg therapy has proved to be efficacious in the case of many autoimmune neuropathies. At present, IVIg is the main first-line therapy indicated for Guillain-Barré syndrome, chronic inflammatory demyelinating neuropathy, and multifocal motor neuropathy. Long-term studies on CIDP treatment with IVIg have shown that this treatment leads to significant short-term and long-term improvement. ${ }^{26}$ Long-term studies on MMN have shown that IVIg does not stop the disease, as deterioration can still occur despite continuing treatment ${ }^{27,28}$ although significantly strong short-term responses to IVIg occur; however, the long-term success rates are very heterogeneous. ${ }^{29}$

In this study, we report on the short and long term therapeutic responses of patients with chronic ataxic neuropathy associated with anti-GD1b antibodies including patients with antidisialosyl antibodies to IVIg.

Nine of the 13 patients improved in response to IVIg infusions, and this improvement persisted in 6 cases. However, as shown in table 1, the improvement was incomplete, amounting in most cases to a gain of about one point in the INCAT disability score. These results are in keeping with those obtained in a randomized placebo-controlled trial on a large series of patients with CIDP. ${ }^{26} \mathrm{~A}$ recent study on a small series of cases also showed that prompt recovery occurred in patients with acute sensory ataxic neuropathy treated with antiGD1b antibodies. The sensory nerve action potentials improved in these patients from undetectable to normal within 3 months and initial signs of recovery were observed as early as week one. $^{30}$

We proposed the diagnosis of CANOMAD for patient no. 5 who fulfilled all criteria for this syndrome according to Willison et al. ${ }^{10}$ However, the purpose of the CANOMAD acronym, 
and indeed any acronym used in clinical practice is in part to alert clinicians to the range of clinical presentations they might expect to see in a syndrome. It is very common for part to be missing, or additional parts to be present, without removing value of an acronym or syndrome. Moreover, some clinical, electrophysiological, or biological marker of the disease may appear later during the follow-up as it was the case in this study. In this way, patients nos. 1, 2, 3, 4 and 7 also may be considered as CANOMAD.

AAN electrophysiological criteria ${ }^{25}$ for the diagnosis of demyelinating neuropathy take into account only motor NCS variables. According to the latter criteria, the 3 patients with demyelinating neuropathy improved in response to IVIg. Two of these 3 patients had antiGM1 IgM autoantibodies but their clinical presentation was similar to the other patients. Interestingly, 6 of the 10 patients with normal NCS or with only mild abnormalities suggesting a demyelination neuropathy (however not fulfilling AAN criteria) also did so. It is worth noting that 2 patients were definitely found at the last motor NCS to have demyelinating neuropathy, although their motor NCS findings were normal at the first examination. The only patient with axonal neuropathy included in this study was refractory to IVIg therapy. NCS may therefore help to predict IVIg responsiveness in patients with neuropathies of this kind. It seems likely that the severity of the damage induced by antiganglioside antibodies can vary from reversible functional impairment via partial axonal injury to complete axonal transection with subsequent Wallerian degeneration. The degree of damage sustained is presumably reflected in the severity of the disease and the patients' subsequent recovery.

This study was an uncontrolled retrospective study. However, However, these neuropathies are rare and series such as this one nevertheless provide useful information about the range of 
responses to IVIg obtained in patients with these neuropathies. One important clinical aspect to which this study leads, in keeping with previous studies, ${ }^{3,16,17,20,31}$ is that anti-GD1b antibodies should be measured in all patients with otherwise idiopathic sensory ataxic neuropathies, even in the absence of monoclonal IgM paraprotein or demyelinating features detected at NCS or features of CANOMAD.

Only 1 of the 4 patients treated with corticosteroids during 6 months improved transiently. Plasmapheresis was not attempted as a means of treating these neuropathic patients. Azathioprine was used in 3 during 12 months patients without success.

In conclusion, screening for anti-GD1b antibodies should be carried out on all patients with chronic sensory ataxic neuropathy. The results obtained in study show that IVIg is often an effective means of treating chronic ataxic neuropathy associated with anti-GD1b antibodies: partially successful results were obtained in the short and these positive responses were mostly sustained in the long term, although the infusions had to be continued. 


\section{REFERENCES}

1. Arai M, Yoshino H, Kusano Y et al. Ataxic polyneuropathy and anti-Pr2 IgM kappa M proteinemia. Journal of neurology. 1992;239:147-151

2. Brindel I, Preud'homme JL, Vallat JM et al. Monoclonal IgM reactive with several gangliosides in a chronic relapsing polyneuropathy. Neuroscience letters. 1994;181:103-106

3. Daune GC, Farrer RG, Dalakas MC, Quarles RH. Sensory neuropathy associated with monoclonal immunoglobulin $\mathrm{M}$ to GD1b ganglioside. Annals of neurology. 1992;31:683-685

4. Ilyas AA, Quarles RH, Dalakas MC et al. Monoclonal IgM in a patient with paraproteinemic polyneuropathy binds to gangliosides containing disialosyl groups. Annals of neurology. 1985;18:655-659

5. Obi T, Murakami T, Takatsu M et al. Clinicopathological study of an autopsy case with sensory-dominant polyradiculoneuropathy with antiganglioside antibodies. Muscle \& nerve. 1999;22:1426-1431

6. Umehara F, Kore-Eda Y, Arime $\mathrm{T}$ et al. Chronic sensory ataxic neuropathy and ophthalmoplegia with oculomotor nerve hypertrophy associated with IgM antibodies against gangliosides containing disialosyl groups. Journal of neurology, neurosurgery, and psychiatry. 1997;62:673-674

7. Willison HJ, Paterson G, Veitch $J$ et al. Peripheral neuropathy associated with monoclonal IgM anti-Pr2 cold agglutinins. Journal of neurology, neurosurgery, and psychiatry. 1993;56:1178-1183

8. Yuki N, Miyatani N, Sato S et al. Acute relapsing sensory neuropathy associated with IgM antibody against B-series gangliosides containing a GalNAc beta 1-4(Gal3-2 alpha NeuAc8-2 alpha NeuAc)beta 1 configuration. Neurology. 1992;42:686-689

9. Susuki K, Yuki N, Hirata K. Features of sensory ataxic neuropathy associated with anti-GD1b IgM antibody. Journal of neuroimmunology. 2001;112:181-187

10. Willison HJ, O'Leary $\mathrm{CP}$, Veitch $\mathrm{J}$ et al. The clinical and laboratory features of chronic sensory ataxic neuropathy with anti-disialosyl IgM antibodies. Brain. 2001;124:1968-1977

11. Kusunoki S, Chiba A, Tai T, Kanazawa I. Localization of GM1 and GD1b antigens in the human peripheral nervous system. Muscle \& nerve. 1993;16:752-756

12. Kusunoki S, Mashiko H, Mochizuki N et al. Binding of antibodies against GM1 and GD1b in human peripheral nerve. Muscle \& nerve. 1997;20:840-845

13. Kusunoki S, Hitoshi S, Kaida $\mathrm{K}$ et al. Monospecific anti-GD1b IgG is required to induce rabbit ataxic neuropathy. Annals of neurology. 1999;45:400-403

14. Kobayashi M, Kato K, Funakoshi K et al. Neuropathology of paraneoplastic neuropathy with anti-disialosyl antibody. Muscle \& nerve. 2005;32:216-222

15. Carpo M, Pedotti R, Lolli F et al. Clinical correlate and fine specificity of anti-GQ1b antibodies in peripheral neuropathy. Journal of the neurological sciences. 1998;155:186-191

16. Delval A, Stojkovic T, Vermersch P. Relapsing sensorimotor neuropathy with ophthalmoplegia, antidisialosyl antibodies, and extramembranous glomerulonephritis. Muscle \& nerve. 2006;33:274-277

17. Marfia GA, Pachatz C, Terracciano C et al. Subacute demyelinating polyneuropathy in B-cell lymphoma with IgM antibodies against glycolipid GD1b. Neurol Sci. 2005;26:355-357 
18. Mitsui Y, Kusunoki S, Hiruma S et al. Sensorimotor polyneuropathy associated with chronic lymphocytic leukemia, IgM antigangliosides antibody and human T-cell leukemia virus I infection. Muscle \& nerve. 1999;22:1461-1465

19. Ponsford S, Willison $\mathrm{H}$, Veitch $\mathrm{J}$ et al. Long-term clinical and neurophysiological follow-up of patients with peripheral, neuropathy associated with benign monoclonal gammopathy. Muscle \& nerve. 2000;23:164-174

20. Serrano-Munuera C, Rojas-Garcia R, Gallardo E et al. Antidisialosyl antibodies in chronic idiopathic ataxic neuropathy. Journal of neurology. 2002;249:1525-1528

21. Siddiqui K, Cahalane E, Keogan M, Hardiman O. Chronic ataxic neuropathy with cold agglutinins: atypical phenotype and response to anti-CD20 antibodies. Neurology. 2003;61:1307-1308

22. Hughes R, Bensa S, Willison $\mathrm{H}$ et al. Randomized controlled trial of intravenous immunoglobulin versus oral prednisolone in chronic inflammatory demyelinating polyradiculoneuropathy. Annals of neurology. 2001;50:195-201

23. Attarian S, Azulay JP, Chabrol B et al. Neonatal lower motor neuron syndrome associated with maternal neuropathy with anti-GM1 IgG. Neurology. 2004;63:379-381

24. Escande-Beillard N, David MJ, Portoukalian J et al. A sensitive flow cytometry method for anti-GM1 antibodies detection. Journal of neuroimmunology. 2002;125:163-169

25. Research criteria for diagnosis of chronic inflammatory demyelinating polyneuropathy (CIDP). Report from an Ad Hoc Subcommittee of the American Academy of Neurology AIDS Task Force. Neurology. 1991;41:617-618

26. Hughes RA, Donofrio P, Bril V et al. Intravenous immune globulin (10\% caprylatechromatography purified) for the treatment of chronic inflammatory demyelinating polyradiculoneuropathy (ICE study): a randomised placebo-controlled trial. Lancet neurology. 2008;7:136-144

27. Taylor BV, Wright RA, Harper CM, Dyck PJ. Natural history of 46 patients with multifocal motor neuropathy with conduction block. Muscle \& nerve. 2000;23:900908

28. Van den Berg-Vos RM, Franssen H, Wokke JH, Van den Berg LH. Multifocal motor neuropathy: long-term clinical and electrophysiological assessment of intravenous immunoglobulin maintenance treatment. Brain. 2002;125:1875-1886

29. Leger JM, Viala K, Cancalon F et al. Intravenous immunoglobulin as short- and longterm therapy of multifocal motor neuropathy: a retrospective study of response to IVIg and of its predictive criteria in 40 patients. Journal of neurology, neurosurgery, and psychiatry. 2008;79:93-96

30. Notturno F, Caporale CM, Uncini A. Acute sensory ataxic neuropathy with antibodies to GD1b and GQ1b gangliosides and prompt recovery. Muscle \& nerve. 2008;37:265268

31. Susuki K, Yuki N, Hirata K. Fine specificity of anti-GQ1b IgG and clinical features. Journal of the neurological sciences. 2001;185:5-9 
Table 1: Patients' main clinical characteristics and responses to IVIg. Sensory ataxic neuropathy associated with anti-disialosyl IgM antibodies was diagnosed in 7 patients (nos. 1-7). Patient 5 fulfilled criteria for CANOMAD.

Abbreviations: AN, axonal neuropathy; CANOMAD, chronic ataxic neuropathy, ophthalmoplegia, IgM paraprotein, cold agglutinins and disialosyl antibodies; DN, demyelinating neuropathy; INCAT, inflammatory neuropathy causes and treatment disability score; MA, mild abnormalities; N, normal; NCS, nerve conduction study; P, progressive; R, relapsing.

\section{$\underline{\text { INCAT Disability Scale }}$}

$\underline{\text { Arm disability }}$

$0=$ No upper limb problems; $1=$ Symptoms, in one or both arms, not affecting the ability to perform any of the following functions: doing; all zips and buttons; washing or brushing hair; using a knife and fork together; and handling small coins; $2=$ Symptoms, in one arm or both arms, affecting but not preventing any of the above-mentioned functions; $3=$ Symptoms, in one arm or both arms, preventing one or two of the above-mentioned functions; $4=$ Symptoms, in one arm or both arms, preventing; three or all of the functions listed, but some purposeful; movements still possible; 5 = Inability to use either arm for any purposeful movement.

$\underline{\text { Leg disability }}$ $0=$ Walking not affected; $1=$ Walking affected, but walks independently outdoors; $2=$ Usually uses unilateral support (stick, single crutch, one arm) to walk outdoors; $3=$ Usually uses bilateral support (sticks, crutches, frame, two arms) to walk outdoors; 4 = Usually uses wheelchair to travel outdoors, but able to stand and walk a few steps with help; $5=$ Restricted to wheelchair, unable to stand and walk a few steps with help. 
$\underline{\text { Overall disability }=\text { Sum of arm and leg disability }}$

Table 2: Laboratory findings.

Patients' sera were tested by performing an ELISA to detect the presence of auto-antibodies against GD1b, GD1a, GQ1b, GM1 and GM2 of IgG and IgM isotypes. ELISA results are expressed as the inverse of the last dilution giving a value above the threshold and all quoted results are IgM. Results $<20$ was considered as negative (-). 
$\underline{\text { Table } 1}$

\begin{tabular}{|c|c|c|c|c|c|c|c|}
\hline Patients & $\begin{array}{l}\text { Sex/age } \\
\text { at onset }\end{array}$ & $\begin{array}{c}\text { Follow-up } \\
\text { time } \\
\text { (months) }\end{array}$ & Form & $\begin{array}{l}\text { Cranial nerve } \\
\text { involvement }\end{array}$ & $\begin{array}{l}\text { Motor } \\
\text { NCS }\end{array}$ & $\begin{array}{c}\text { Initial } \\
\text { INCAT } \\
\text { before IVIg }\end{array}$ & $\begin{array}{l}\text { last INCAT } \\
\text { after IVIg }\end{array}$ \\
\hline 1 & $\mathrm{M} / 60$ & 78 & $\mathrm{R}$ & dysphonia & $\mathrm{N}$ & 6 & 5 \\
\hline 2 & $\mathrm{~F} / 51$ & 23 & $\mathrm{P}$ & & $\mathrm{N}$ & 1 & 1 \\
\hline 3 & $F / 67$ & 20 & $\mathrm{P}$ & dysphonia & MA & 4 & 3 \\
\hline 4 & $\mathrm{M} / 36$ & 96 & $\mathrm{R}$ & $\begin{array}{l}\text { ophthalmoplegia; } \\
\text { facial paresis }\end{array}$ & $\mathrm{N}$ & 5 & 4 \\
\hline 5 & $\mathrm{~F} / 60$ & 36 & $\mathrm{P}$ & ophthalmoplegia & $\mathrm{N}$ & 8 & 4 \\
\hline 6 & $\mathrm{M} / 81$ & 74 & $\mathrm{P}$ & & $\mathrm{AN}$ & 3 & 3 \\
\hline 7 & $\mathrm{M} / 51$ & 17 & $\mathrm{R}$ & $\begin{array}{c}\text { dysphonia, } \\
\text { dysphagia, } \\
\text { ophthalmoplegia }\end{array}$ & $\mathrm{DN}$ & 6 & 5 \\
\hline 8 & F/66 & 42 & $\mathrm{P}$ & & $\mathrm{N}$ & 2 & 2 \\
\hline 9 & $\mathrm{M} / 52$ & 34 & $\mathrm{P}$ & & MA & 4 & 3 \\
\hline 10 & $\mathrm{M} / 70$ & 29 & $\mathrm{P}$ & & $\mathrm{N}$ & 3 & 3 \\
\hline 11 & $\mathrm{~F} / 42$ & 69 & $\mathrm{R}$ & $\begin{array}{l}\text { diplopia; trigeminal } \\
\text { neuralgia }\end{array}$ & DN & 2 & 1 \\
\hline 12 & $F / 48$ & 36 & $P$ & & $\mathrm{~N}$ & 2 & 1 \\
\hline 13 & $\mathrm{M} / 36$ & 36 & $\mathrm{P}$ & & DN & 2 & 0 \\
\hline Mean & & & & & & 3.7 & 2.7 \\
\hline
\end{tabular}


$\underline{\text { Table } 2}$

\begin{tabular}{cccccccccc}
\hline Patients & & & & & & & Monoclonal & Cold & CSF protein \\
\hline & GD1b & GD3 & GT1b & GQ1b & GMI & GD1a & Gammopathy & agglutinins & Level (gr/l) \\
\hline 1 & 160 & 80 & 80 & 180 & - & - & IgM Kappa & & 0.98 \\
2 & 640 & 640 & 640 & 320 & - & - & IgM Kappa & + & 0.59 \\
3 & 80 & 320 & 320 & 320 & - & - & IgM Kappa & + & 0.36 \\
4 & 40 & 40 & 40 & 40 & - & - & & + & 0.6 \\
5 & 640 & 640 & 320 & 1280 & - & - & IgM Lambda & + & 0.66 \\
6 & 80 & 320 & 320 & 320 & - & - & & & 0.85 \\
7 & 640 & - & 40 & - & - & - & IgM Kappa & & ND \\
8 & 40 & - & - & 80 & - & - & & & 0.12 \\
9 & 80 & - & - & - & - & - & & & 0.23 \\
10 & 160 & - & - & 80 & - & - & & & 0.28 \\
11 & 20 & - & - & - & 80 & - & IgM Kappa & & 0.8 \\
12 & 40 & - & - & - & - & - & & & 1.3 \\
13 & 40 & - & - & - & 160 & - & & & \\
\hline
\end{tabular}

